\title{
Thermoacoustically driven flame motion and heat release variation in a swirl-stabilized gas turbine burner investigated by LIF and chemiluminescence
}

\author{
W. Hubschmid · R. Bombach • A. Inauen · F. Güthe • \\ S. Schenker · N. Tylli · W. Kreutner
}

Received: 1 July 2005 / Revised: 27 February 2008 / Accepted: 2 March 2008 / Published online: 26 April 2008

(C) Springer-Verlag 2008

\begin{abstract}
Laser-induced fluorescence and chemiluminescence, both phase-locked to the dominant acoustic oscillation, are used to investigate phenomena related to thermoacoustic instability in a swirl-stabilized industrial scale gas turbine burner. The observed sinusoidal phaseaveraged flame motion in axial (main flow) direction is analyzed using different schemes for defining the flame position. Qualitative agreement between experimental data and theoretical analysis of the observed flame motion is obtained, interpreted as originating primarily from variation of the burning velocity. The heat release variation during an acoustic cycle is determined from the sinusoidally varying total $\mathrm{OH}^{*}$ chemiluminescence intensity.
\end{abstract}

\section{List of symbols}

$\begin{array}{ll}A_{0}, A_{1} & \text { parameters of gas flow (Eq. A4) } \\ \mathrm{BZ} & \text { bottom flame zone } \\ c & \text { adiabatic sound velocity } \\ c_{\text {fuel }} & \begin{array}{l}\text { fuel concentration } \\ \mathrm{CZ}\end{array} \\ \mathrm{CL} & \text { central flame zone } \\ \mathrm{CM} & \text { chemiluminescence } \\ D & \text { diameter of burner } \\ d & \text { diameter of combustion chamber } \\ \Delta h_{f}^{m} & \text { molar formation enthalpy } \\ I_{\mathrm{CL}} & \text { CL intensity }\end{array}$

W. Hubschmid $(\varangle) \cdot$ R. Bombach · A. Inauen $\cdot$ S. Schenker . N. Tylli · W. Kreutner

Paul Scherrer Institut, 5232 Villigen PSI, Switzerland

e-mail: walter.hubschmid@psi.ch

F. Güthe

ALSTOM (Schweiz) AG, 5405 Baden-Dättwil, Switzerland
LIF laser-induced fluorescence

$p_{\text {ac }} \quad$ acoustic pressure

$\Delta \dot{Q} \quad$ heat release rate into a volume element

$s_{\mathrm{T}} \quad$ turbulent flame speed (flame velocity relative to gas flow)

$S r=\frac{v D}{u} \quad$ Strouhal number

SZ shear layer zone

$T_{\text {air }} \quad$ inlet air temperature

$t \quad$ time

TZ top flame zone

$u \quad$ inlet gas flow velocity

$u^{\prime} \quad$ turbulence intensity

$\Delta V \quad$ volume element

$v_{\mathrm{b}} \quad$ burning velocity

$v_{\text {gas }, 0}$ stationary part of phase-averaged gas flow velocity

$v_{\text {gas }}^{\text {tot }} \quad$ phase-averaged gas flow velocity

$v_{r} \quad$ axial projection of turbulent flame speed

$\delta \bar{v}_{r} \quad$ amplitude of variation of $v_{r}(t)$

$\bar{v}_{r} \quad$ temporal average of $v_{r}$

$v_{\mathrm{var}} \quad$ phase-dependent gas flow velocity

$x, y \quad$ transverse coordinates

$\Delta x \Delta y \quad$ cross section element of combustion chamber

$z \quad$ axial coordinate

$z_{\mathrm{fl}} \quad$ flame position in axial direction

$z_{0} \quad$ temporal average of $z_{\mathrm{fl}} z_{\mathrm{fl}, \max }$ (min) maximum (minimum) of $z_{\mathrm{fl}} \Delta z_{\mathrm{fl}}=z_{\mathrm{fl}, \text { max }}-z_{\mathrm{fl} \text {,min }}$

$\dot{z}_{\mathrm{fl}}(t) \quad$ axial component of flame velocity in laboratory

$\alpha \quad$ phase angle of maximal flame velocity relative to gas flow

$\gamma \quad$ ratio of heat capacities $\left(c_{p} / c_{\mathrm{v}}\right)$

$\chi \quad$ phase angle of maximum of heat release rate

$\delta$ phase shift between the variation of the heat release and the $\mathrm{OH}$ LIF intensity $\zeta=A_{1} / \omega$

$\vartheta \quad$ angle between flame front and $x-y$ plane 
$\rho_{0} \quad$ average gas density

$\phi \quad$ fuel-air equivalence ratio

$\varphi \quad$ phase angle of forward zero crossing of flame motion

$\psi \quad$ phase angle of maximum LIF intensity

$\omega \quad$ angular frequency of sound

\section{Introduction}

Modern industrial gas turbines are operated at very lean premixed flame conditions in order to reduce the emission of $\mathrm{NO}_{x}$. In this range of operation the occurrence of thermoacoustic instabilities is favored. The temporal variation of the heat release rate is known to be the main source of pressure waves in the system. Resonance of the combustor and feedback of the pressure variation on both the fuel/air mixing and the turbulence fluctuation lead to selective amplification of distinct oscillation frequencies. One important engineering goal is to devise a theoretical description of the observed phenomena like the periodic variation of the heat release and of the burning velocity, and to allow predictions of the growth conditions for pulsation modes and of the asymptotic pressure level of the sound oscillation. Current theoretical descriptions use simplified models as a basis for numerical calculations. Therefore, experimental information on thermo-acoustically unstable combustion processes is needed in order to validate the numerical simulations, as well as to guide the further development of burners and combustors and of the numerical codes. Because of their non-intrusiveness, optical measurement techniques, like laser-induced fluorescence (LIF), chemiluminescence (CL), or particle imaging velocimetry (PIV) have been widely employed to investigate combustion instabilities in gas turbines.

A comprehensive overview on theory and phenomena of instabilities in gas turbine engines is given in the recent book edited by Lieuwen and Yang (2005). See here especially the articles by Ducruix et al. (2005), Huang et al. (2005), Menon (2005), Lieuwen (2005), and Dowling and Stow (2005). Earlier, Paschereit et al. (2000, 2001, 2002), Krüger et al. (2001), and Krebs et al. (2002b), among others, discussed specific problems of combustion instabilities in gas turbines. A review on combustion dynamics and its control can, e.g., be found in Candel (2002). Experimental results on combustion instabilities, focussing mainly on observations of the variation of the heat release and the fuel concentration with the acoustic oscillation, were reviewed by Lee and Santavicca (2005).

In order to have guidelines for experiments on thermoacoustic instabilities in combustion and to understand and interpret the phenomena observed in the experiments, a look at the theory of sound generation in combustion is needed. The fundamental equation is the equation for the generation and the propagation of sound waves. In the case that only the variation of the heat release rate is considered as source of sound, the wave equation has the following form (Ingard 1968):

$\frac{\partial^{2} p_{\mathrm{ac}}}{\partial t^{2}}-\nabla\left(\mathrm{c}^{2} \nabla p_{\mathrm{ac}}\right)=(\gamma-1) \frac{\partial}{\partial t} \frac{\Delta \dot{Q}}{\Delta V}$

In Eq. (1) $p_{\mathrm{ac}}$ is the sound pressure, $\Delta \dot{Q}$ is the heat release rate in the volume element $\Delta V=\Delta x \Delta y \Delta z$; it equals the rate of change of sensible enthalpy, which is generated by the chemical reaction, into this volume element. By convention, $x$ and $y$ are the transverse coordinates, and $z$ is the axial coordinate, which coincides with the main flow direction (see Fig. 2). Furthermore, the ratio $\gamma$ of specific heats and the adiabatic sound velocity $c$ appear in Eq. (1). Other source terms, as the turbulence source term, are neglected in Eq. (1), as they are assumed to be distinctly smaller than the heat release term. The dissipation terms are not written explicitly either. In the case of sound pressure amplitudes that are not negligible compared to the average pressure, a generalized non-linear sound equation has to be applied instead of Eq. (1) (Poinsot and Veynante 2001).

The heat release rate per cross section element $\Delta x \Delta y$ of the combustor chamber is

$\frac{\Delta \dot{Q}}{\Delta x \Delta y}=-c_{\text {fuel }}(t, x, y) \frac{v_{\mathrm{b}}(t, x, y)}{\cos \vartheta} \Delta h_{f}^{\mathrm{m}}$.

In Eq. (2), $v_{\mathrm{b}}(t, x, y)$ is the burning velocity, i.e. the volume of reactant gas burnt per cross section unit of the flame brush and per time unit (the flame brush, or shortly flame, is assumed to be infinitely small), $\vartheta$ is the angle of the flame to the $x-y$ plane, $c_{\text {fuel }}(t, x, y)$ is the fuel concentration at the coordinates $x$ and $y$ of the flame, and $\Delta h_{f}^{\mathrm{m}}$ is the (negative) molar reaction enthalpy at standard temperature.

According to Eq. (2), variation of local heat release may originate from either variation of $v_{\mathrm{b}}(t, x, y), c_{\text {fuel }}(t, x, y)$, and/or $\cos \vartheta$, i.e. the (infinitesimal) flame area. Variation of $v_{\mathrm{b}}(t, x, y)$ with the sound pressure can originate from various sources. According to Filatyev et al. (2005), the burning velocity $v_{\mathrm{b}}(t, x, y)$ is closely related to the turbulent flame speed $s_{\mathrm{T}}$, which is the speed of the flame front, respectively, of some iso-line of the reaction variable, relative to the flow. $s_{\mathrm{T}}$ itself depends on the laminar flame speed $s_{\mathrm{L}}$ and on the turbulence intensity $u^{\prime}$, which both vary with the presence of sound waves: 'The laminar flame speed $s_{\mathrm{L}}$ depends on the fuel concentration and on the temperature, and therefore on the sound pressure; on the other hand Poinsot et al. (1987) and Poinsot and Veynante (2001) showed that sound waves may generate vortices and 
thus enlarge the turbulence intensity $u^{\prime}$. Explicit relations between $s_{\mathrm{T}}, s_{\mathrm{L}}$ and $u^{\prime}$ are given by Zimont and Lipatnikov (1995), Polifke et al. (2000), or Filatyev et al. (2005).

Variation of the fuel concentration with the fluctuating pressure of acoustic waves originates from the effect that fuel concentration is modulated by the variation of the sound pressure at the injector of the burner (see Schuermans et al. 2004). With some time delay the induced variation of the fuel concentration reaches the flame. Biagioli et al. (2007) indicate that from the unsteady flame anchoring, sound pressure oscillations also may generate variations of the infinitesimal flame area, i.e. of the angle $\vartheta$.

The temporal variation of $c_{\text {fuel }}(t, x, y)$ can be observed by either an absorption measurement or by observing the LIF of a tracer added to the fuel. The axial projection $v_{r}$ of $s_{\mathrm{T}}(t, x, y, z)$ can be derived from LIF measurements of flame species, as motion in axial direction of the flame. As $s_{\mathrm{T}}(t, x, y, z)$ is defined as velocity relative to the gas, for the determination of $s_{\mathrm{T}}(t, x, y, z)$ also the gas flow velocity has to be measured. By observing the phase-averaged flame zone, the angle $\vartheta$ can be determined, too.

Lee et al. (2000) were among the first to determine the temporal variation of the heat release in unstable combustion. They determined the heat release in a lean premixed model combustor by means of $\mathrm{CL}$ of $\mathrm{OH}^{*}$, and compared it with values derived from the flame surface density as obtained from OH LIF. The authors show that there is good agreement between these distinct measurements. Ferguson et al. (2001) applied high-speed $\mathrm{OH}^{*}$ and $\mathrm{CH}^{*} \mathrm{CL}$ imaging to stable and unstable conical flames in a Rijke Tube combustor in order to determine the global heat release rate and the flame surface area, respectively. Krebs et al. (2002a, b) and Khanna et al. (2002) measured the flame response of swirlstabilized flames to externally driven oscillations. Using $\mathrm{OH}^{*} \mathrm{CL}$ as a measure for the heat release rate they compared flame response and incoming velocity fluctuations. Giezendanner et al. (2003) reported on the combination of quasisimultaneous phase-resolved LIF and CL measurements of $\mathrm{OH}, \mathrm{CH}, \mathrm{CH}_{2} \mathrm{O}$, and of $\mathrm{OH}^{*}$ in order to observe phenomena related to combustion instabilities in a swirl-stabilized diffusion burner. Bellows et al. (2006) investigated the saturation of the pressure fluctuations with growing heat release by means of $\mathrm{OH}^{*}$ and $\mathrm{CH}^{*} \mathrm{CL}$.

Measurements of fuel concentrations in unstable combustion have been performed by Venkataraman et al. (1999), who combined phase-resolved $\mathrm{CH}^{*} \mathrm{CL}$ with fuel/ air mixing data obtained by means of LIF measurements of the fuel tracer acetone. They conclude that both, changes in flame area and fluctuations of equivalence ratio drive the combustion instability in their lean premixed bluff-bodystabilized combustor. The technique of acetone LIF has been applied also by Schneiders et al. (2001) to investigate the mixing processes in gas turbine burners.
The focus of this article is the investigation of the phaseaveraged periodic flame motion (phase-averaged: measurements averaged at fixed phase of the investigated acoustic oscillation), which is the consequence of the periodic variation of the burning velocity in thermo-acoustically unstable combustion (cp. comment to Eq. 2). Such flame motion was observed in an industrial scale swirl-stabilized gas turbine burner. Phase-locked LIF of flame species was employed to localize the flame zone and to detect its motion at the prevalent frequency of the acoustic oscillation (Sects. 3.2, 3.3). External sound forcing ranging at levels from zero to maximum power of the loudspeaker system was applied in order to stabilize the acoustic oscillation rendering phase-locking easier. To determine the position of the flame zone, a simultaneous measurement of $\mathrm{OH}$ and $\mathrm{CH}_{2} \mathrm{O}$ would be appropriate (Paul and Najm 1998). For the observation of the flame motion, however, the absolute value of the flame position is not of first relevance; thus each of the two species alone can well be employed. The radical $\mathrm{CH}$ has a rather small concentration at the lean conditions used in gas turbine combustion, so that its use in LIF measurements is excluded. In our investigations, most of the measurements used $\mathrm{OH}$ as indicator for the flame zone; in a few cases, however, the $\mathrm{CH}_{2} \mathrm{O}$ distribution was determined to obtain the flame motion. LIF of $\mathrm{CH}_{2} \mathrm{O}$ is advantageous compared to LIF of $\mathrm{OH}$, if, in addition to the flame position, the phase angle of the maximum of the heat release rate should also be determined. It is probable that the determination of this phase angle by means of LIF of $\mathrm{CH}_{2} \mathrm{O}$ results in a more accurate value for this quantity (cp. the discussion in Sect. 3.2). The phenomenon of phase-averaged flame motion was previously reported at various conferences, cp. Hubschmid et al. (2002) and Schenker et al. (2003). Hassa et al. (2002) observed flame motion by means of $\mathrm{OH}^{*} \mathrm{CL}$ in a liquid fuel combustor operated at pressures up to $20 \mathrm{bar}$. In a premixed swirl-stabilized combustor a periodic motion of the flame was observed by Bellows et al. (2007). Different techniques for quantifying the phase-averaged motion of the flame are presented and compared in this paper. Also, the phase relation between the flame motion and the periodic variation of the heat release rate was determined for a large number of operation conditions. In additional measurements, CL of $\mathrm{OH}^{*}$ was applied for a quantitative determination of the variation of the heat release (Sect. 3.4). Furthermore, by means of LIF of acetone the modulation of the fuel concentration by the acoustic oscillation was observed (Sect. 3.5).

\section{Experimental set-up}

The experiments with $\mathrm{OH}$ LIF and $\mathrm{OH}^{*} \mathrm{CL}$ were performed on a commercial single swirl-stabilized gas turbine 
burner (Alstom EV burner), which was operated at atmospheric pressure with a power of about $700 \mathrm{~kW}$. A schematic drawing of the EV burner is shown in Fig. 1. The burner has been described in detail by Döbbeling et al. (2005). Figure 2 presents a schematic of the burner and combustor together with the optical experimental set-up. The fuel/air supply, upstream of the burner and the exhaust are not shown. Natural gas is injected both along the air slots of the burner cone and from a lance situated in the cone axis. The air is preheated $\left(673 \mathrm{~K}<T_{\text {air }}<743 \mathrm{~K}\right)$ and enters from the plenum through the slots, which separate the two half-cones of the burner. The temperature of the air was measured by thermocouples right after the electric preheaters and prior to the burner and fuel-air mixing section. Fuel and air mix in the burner cone and enter the cylindrical combustion chamber with a high swirl. After the sudden expansion into the combustion chamber (about 1:4 in area), recirculation zones are formed in the central and in the outer regions. These are confirmed by numerical simulations (Flohr et al. 2002; Biagioli 2006), as well as by LDA measurements in water flow experiments (Paschereit et al. 1999) and by PIV measurements (Schuermans et al. 2006). A section of the combustion chamber, from the burner exit plane to about one chamber diameter downstream, is made of UV transparent quartz glass and cooled by air.

Depending on the operating conditions of the burner, acoustic oscillations at distinct frequencies are established inside the combustion chamber, one of them at about $S r=0.51$ being clearly dominant. The sound pressure in the combustion chamber was measured with a calibrated water-cooled microphone positioned close to the flame zone, i.e. approximately 1.5 chamber diameters downstream of the burner exit plane. Forcing the dominant frequency with two sets of four loudspeakers each (total power of $1,200 \mathrm{~W}$ ) enhanced the continuity of the combustion instability. This facilitated triggering of the laser pulses and was applied for most of the experiments. One of the loudspeaker sets was mounted upstream of the burner in

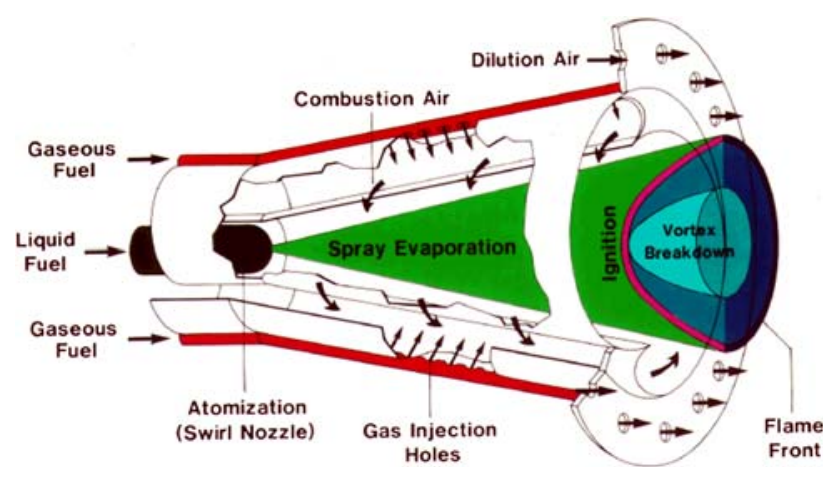

Fig. 1 Schematic drawing of the Alstom EV burner

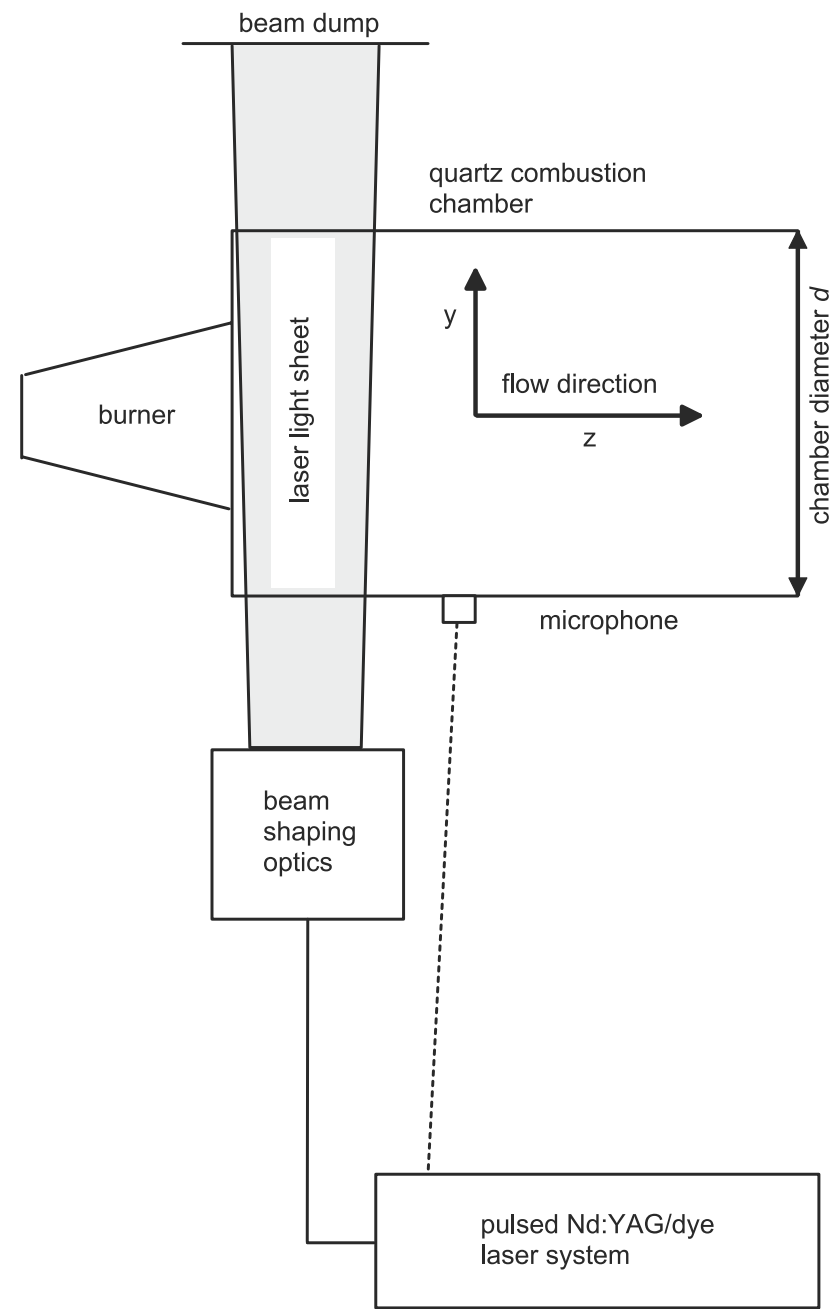

Fig. 2 Scheme of the burner, combustor, together with the optical experimental set-up

the air plenum and the other one at the exhaust. An example of an unforced experiment is described in Fig. 5a, b.

For the OH LIF experiments, the frequency-doubled light of a pulsed Nd:YAG/dye laser system (Quantel YG781/TDL50) at $286 \mathrm{~nm}$ was used to excite the $\mathrm{P}_{1}(7)$ line of the $\mathrm{A} \leftarrow \mathrm{X}(1 \leftarrow 0)$ transition of the $\mathrm{OH}$ radicals. This line is rather insensitive to temperature variations in the range considered. The repetition rate of the Nd:YAG laser was fixed to $20 \pm 0.2 \mathrm{~Hz}$. A specially designed phase-lock loop (PLL) filter allowed for locking of the laser repetition rate to the dominant thermo-acoustic frequency. By the experimental conditions the value of the phase-angle of the laser pulses with respect to the phase angle of the acoustic oscillation is defined only up to an unknown constant. The period of the acoustic oscillation was divided into 24 intervals, i.e. $15^{\circ}$ phase resolutions. At each phase angle of one measurement series, 100 single pulse images as well as 10 images of 100 pulses summed up on the CCD chip were recorded. The laser beam was shaped by appropriate 
combination of cylindrical and spherical lenses into a slightly divergent light sheet with a width of about $110 \mathrm{~mm}$ and a thickness of approximately $0.2 \mathrm{~mm}$, propagating from bottom to top through the combustion chamber tube. The laser light sheet was oriented in the $y-z$ plane, $y$ being the propagation direction of the laser light, and $z$ being the symmetry axis of the tube, i.e. the main flow direction (see Fig. 2). The OH LIF signal was detected normal to the plane of the light sheet using an intensified CCD camera (LaVision FlameStar II, gate: $40 \mathrm{~ns}$ ) equipped with a band pass filter centered at $310 \mathrm{~nm}$ (FWHM $14 \mathrm{~nm}$ ). The filter chosen allowed recording several rotational lines of the $(1 \rightarrow 0)$ transition of $\mathrm{OH}$. All images were corrected for camera background.

For most of the investigated operation conditions, in addition to $\mathrm{OH} \mathrm{LIF}$, also 2-D line-of-sight $\mathrm{CL}$ of $\mathrm{OH}^{*}$ was registered. Phase delay and camera set-up were the same for the $\mathrm{OH}^{*} \mathrm{CL}$ measurements; the camera exposure time was $0.1 \mathrm{~ms}$. The detection area in flow direction was larger for the CL measurements as compared to the LIF recordings, as they are not limited by the width of a laser light sheet. In the spectral range of the band pass filter used, one has to expect also $\mathrm{CL}$ of $\mathrm{CO}_{2}{ }^{*}$ (Nori and Seitzman 2007). $\mathrm{CO}_{2}{ }^{*}$ shows broadband emission resulting in a minor addition to the detected $\mathrm{OH}^{*} \mathrm{CL}$ only. This does not disturb the final results, as we rely always on relative intensities.

The supplementary experiments with LIF of formaldehyde $\left(\mathrm{CH}_{2} \mathrm{O}\right)$ were performed with a modified EV burner, and with a modified combustion chamber, which is closer to the configurations in a real gas turbine. Especially, the stainless steel combustion chamber was of rectangular shape and was water-cooled. This design allowed for mounting of one set of four loudspeakers (total power $600 \mathrm{~W}$ ) in the air plenum upstream of the burner mixing section only. Optical access was provided by two large quartz windows, embedded into the bottom sidewall of the combustion chamber. They are situated as close as possible to the burner edge where sudden expansion takes place. Several water-cooled microphones allowed for the measurement of both, the frequency and the amplitude of the acoustic oscillations. For $\mathrm{CH}_{2} \mathrm{O}$ LIF the frequency doubled output of the same laser system, except for the dye (pyridine 1), was used to excite into the $\mathrm{A} \leftarrow \mathrm{X} 4_{0}^{1}$ transition at around $352.5 \mathrm{~nm}$. Fluorescence of several vibronic emission bands in the spectral range of $400-550 \mathrm{~nm}$ was detected using the same camera type equipped with a combination of Schott filters (KV389 and BG39/3).

The fuel-air mixing and the influence/effect of the modulation of the sound wave were investigated by LIF measurements of acetone, which was added to the fuel prior to mixing as tracer. These experiments were also carried out with a modified EV burner. This burner had an additional mixing section, partly made of UV transparent quartz, prior to the sudden expansion into the combustion chamber. The laser light sheet entered from below covering the entire length of the transparent section along the symmetry axis. Acetone was excited using the fourth harmonic of the Nd:YAG laser at $266 \mathrm{~nm}$. Typical tracer mole fractions were below $2 \%$. This low concentration ensured a complete vaporization of the acetone prior to its entering the burner section. Tracer concentration studies showed no saturation effects. Therefore, incomplete vaporization could be excluded. The fluorescence was collected normal to the plane of the laser-light sheet with the camera described above, and equipped with a long pass filter (Schott WG295) to separate the LIF signal from reflected and/or (Rayleigh) scattered light.

In identical operating conditions of the burner, sound pressures in the combustor were clearly higher with acoustic forcing than without forcing. Full forcing resulted in up to four times higher sound pressures than without acoustic forcing. Partial forcing, i.e. only upstream forcing at $70 \%$ of full power of the loudspeakers, resulted in about 1.3-1.7 times higher sound pressures than without. For the same power levels of the loudspeakers, the sound pressures for flows with a flame were by far larger than the ones for flows of preheated air only, where the fuel was replaced by $\mathrm{N}_{2}$. For a typical operation condition, a peak sound pressure of $800 \pm 50 \mathrm{~Pa}$ was measured for the flame compared to $40 \mathrm{~Pa}$ for the airflow only. Thus, the induced sound intensity by the loudspeakers is by far smaller than the sound intensity generated by the unstable burning flame.

The levels of naturally occurring sound pressure were distinctly lower in the burner and combustor used for the $\mathrm{CH}_{2} \mathrm{O}$ LIF experiments than in the original burner and chamber design. Typical peak pressure oscillations of $<300 \mathrm{~Pa}$ were observed. In addition, the influence of forcing was significantly lower due to the combustor design as well as the lower forcing power applied. This complicated the phase-locking of the laser diagnostics equipment to the dominant acoustic oscillation. We suppose that this is the main reason for the observed reduced sinusoidal dependence of the LIF intensity on the acoustic phase. In the meanwhile, an alternative to the phase-locking technique is proposed by Güthe and Schuermans (2007) for circumventing this difficulty. They determine the acoustic phase of each laser pulse and group measurements with similar acoustic phases.

\section{Results and discussion}

\subsection{Flame zone from LIF and from CL}

For some given operation condition, Fig. 3a shows a selection of single pulse LIF images of the $\mathrm{OH}$ distributions. 
Fig. 3 a Selection of four single-pulse LIF intensity distributions of $\mathrm{OH}$ at phase $0^{\circ}$ of the dominant acoustic oscillation. b (rightmost figure) OH LIF image averaged at phase $0^{\circ}$ with classification of the flame sections, i.e. top (TZ), central (CZ) and bottom flame zone (BZ), and the transient flame zones in between. The gas flow is from left to right. Forcing was applied to the acoustic oscillation
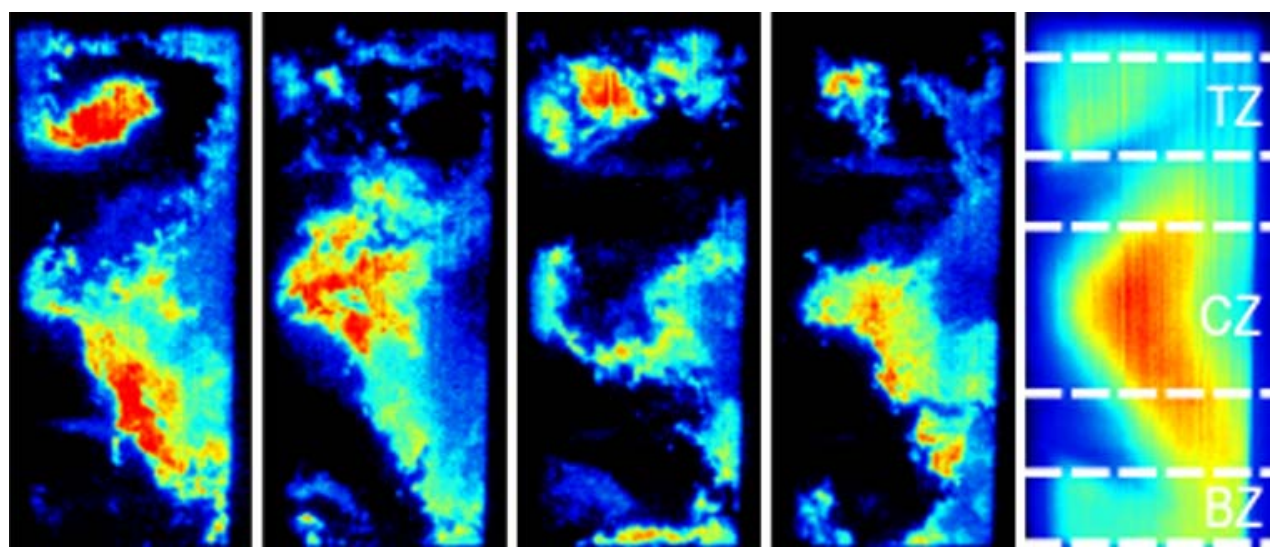

The naturally occurring thermoacoustic oscillations were forced here externally. The images were all taken at one arbitrarily chosen phase angle of the dominant acoustic oscillation. Their vertical extensions correspond to about the diameter of the combustion chamber, apart from a small missing region at the bottom, which was masked by a bolt. The signal distributions and shapes vary strongly from pulse to pulse, and there is no characteristic pattern observed for any of the phase angles considered.

Averaged images of the flame zone, for fixed phases of the dominant acoustic oscillation, reveal a more regular behavior. A periodic variation of the OH LIF intensity and a spatial motion of the $\mathrm{OH}$ zone are observed in the case of acoustic forcing as well as without any forcing. Figure $3 \mathrm{~b}$ shows the phase-averaged OH LIF image for 100 single pulse images of the experiment of Fig. 3a. In Fig. 4a the development of this flame in intervals of $45^{\circ}$ of the phase angle is shown. The section of the $\mathrm{OH}$ distribution visualized by the laser light sheet is a v-shaped domain in the center, with an opening angle of about $40^{\circ}$ with respect to the plane normal to the main flow direction. Additional regions of $\mathrm{OH}$ are seen in the outer re circulation zones. For the same operation conditions, also $\mathrm{OH}^{*} \mathrm{CL}$ was recorded. Figure $4 \mathrm{~b}$, c show the results of the phaseresolved (line-of-sight) CL measurements for the same circumferential orientation of the burner as in the LIF experiment (Fig. 4a) and with the burner rotated by $90^{\circ}$, respectively. The axial asymmetry of the design of the burner is recognized. A general asymmetry of the intensity distribution, i.e. higher CL intensity in the upper part of the figure, is distinctly observable.

For the analysis of the phase-averaged OH LIF measurements, the 2-D distribution of the OH LIF intensity was split into small sub-zones of about 1/30th of the chamber diameter. Some sub-zones both in the center and in the outer zones yielded similar temporal behavior of the LIF a)

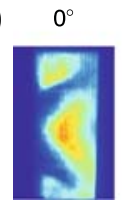

b)

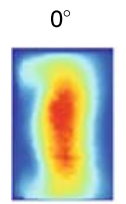

c)

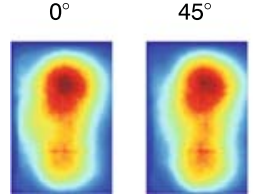

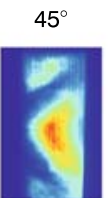

$45^{\circ}$
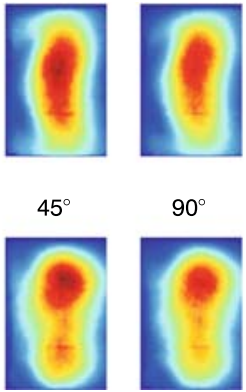

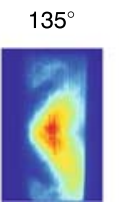

$135^{\circ}$
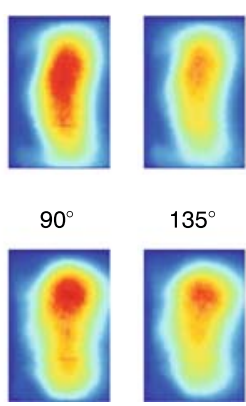

$35^{\circ}$

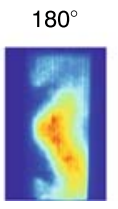

$180^{\circ}$

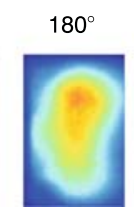

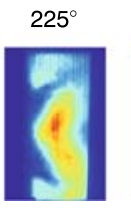

$225^{\circ}$
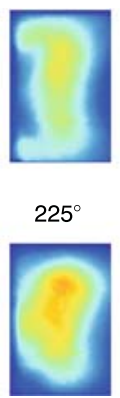
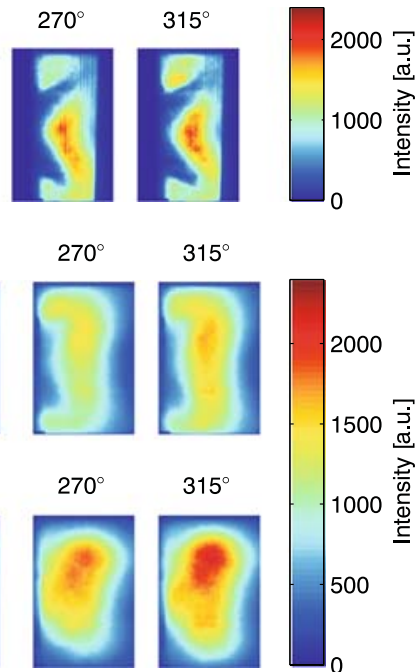

Fig. 4 a Phase-averaged OH LIF intensity measurements at the phases of $0^{\circ}, 45^{\circ}, 90^{\circ}, 135^{\circ}, 180^{\circ}, 225^{\circ}, 270^{\circ}$ and $315^{\circ}$ of the dominant forced acoustic oscillation. $\mathbf{b}$ Corresponding phase-averaged $\mathrm{OH}^{*} \mathrm{CL}$ measurements for the same operating conditions. c Phaseaveraged $\mathrm{OH}^{*} \mathrm{CL}$ measurements with the burner rotated by $90^{\circ}$ compared to $\mathbf{b}$. For both series of CL, the camera position was shifted downstream by about $d / 8$ compared to a. Therefore the images in $\mathbf{b}$ and $\mathbf{c}$ are displayed with an offset with respect to those in a so that corresponding points in the combustion chamber lie on the same vertical line 
intensity and the flame motion. Therefore, these sub-zones were combined to larger sections: in a central flame zone (CZ) and two outer zones close to the burner wall, named bottom (BZ) and top flame zones (TZ; "bottom" and "top" refer to the set-up geometry; see Fig. 3b). BZ and TZ coincide about with the outer recirculation zones of the flow field. The temporal behavior in BZ and TZ differs strongly from the one in $\mathrm{CZ}$, with respect to phase angles and amplitudes of the observed flame motion and variation of the LIF intensity. The temporal behavior in the transient zones in between marks the transition from central to peripheral zones.

The laser light sheet positioned close to the burner exit plane covered the main heat release zone and thus, the main domain of $\mathrm{OH}$ formation. It was shown by measurements shifted downstream by about the sheet width that in smaller concentrations $\mathrm{OH}$ is found also more downstream, especially in the outer recirculation zones. In the central zone, however, the $\mathrm{OH}$ concentration is very small.

From the comparison of the $\mathrm{OH}^{*} \mathrm{CL}$ with the $\mathrm{OH} \mathrm{LIF}$ results (see Fig. 4a), we conclude that attenuation of the laser light along the propagation of the light sheet was on the order of not more than $10 \%$. Actually, for some additionally measured operation conditions, intensity of $\mathrm{OH}$ LIF was even somewhat larger in the TZ than in the BZ. This is in accordance with the $\mathrm{OH}^{*} \mathrm{CL}$ results: the integral $\mathrm{OH}^{*} \mathrm{CL}$ intensity in $\mathrm{TZ}$ was larger by about $10 \%$ than in the BZ. Thus, for the quantities of interest, as phaseaveraged variation of OH LIF intensity, laser light attenuation can be neglected.

In Fig. 5a, c, the difference between operation without and with sound forcing is demonstrated. All other operation conditions were the same, namely $T_{\text {in }}=723 \mathrm{~K}, \phi=0.48$, and $u=40 \mathrm{~m} \mathrm{~s}^{-1}$. In the case of acoustic forcing, the observed peak pressure amplitude was larger by a factor of 1.9: 930 versus $500 \mathrm{~Pa}$. Figure 5a, c show the phaseaveraged $\mathrm{OH}$ LIF intensities as a function of the oscillation phase and integrated over the central flame zone CZ. We observe a variation in OH LIF intensity of about $\pm 6 \%$ and $\pm 17 \%$, respectively, during one oscillation period, with a slight change of the phase for the maximum of intensity. For each of the three zones CZ, BZ and TZ, a sine function can well be fitted to the phase averaged and spatially integrated OH LIF intensity data. In the transition zones the intensity variation is reduced and the phase is shifted somewhat, compared to the $\mathrm{CZ}$, whereas in the $\mathrm{BZ}$ and $\mathrm{TZ}$ averaged LIF intensities vary stronger again. The standard deviations of single-pulse intensity fluctuations, divided by the mean intensity, at a given phase and integrated for $\mathrm{CZ}$, were in the forced case between 26 and $32 \%$ for the various phase angles. Therefore, standard deviations of the mean values are about $3 \%$ for $N=100$ pulses. This agrees

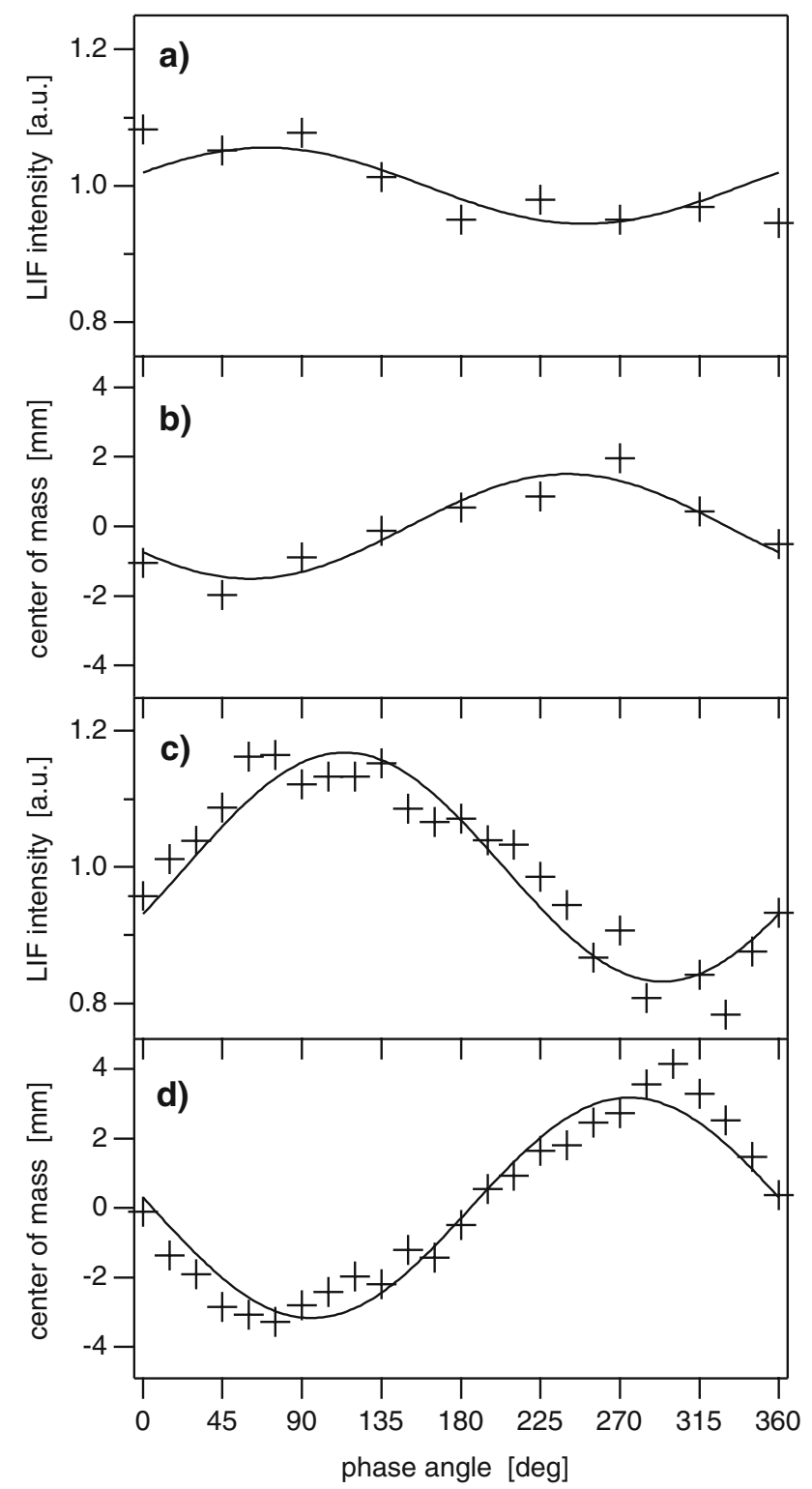

Fig. 5 Variation of $\mathbf{a}$ the $\mathrm{OH}$ LIF intensity and $\mathbf{b}$ the axial coordinate of the center of mass for the OH LIF intensity in the central zone during an oscillation period and their corresponding sinusoidal fit (solid line) for an experiment without sound forcing. c, $\mathbf{d}$ Respective quantities for experiment with same operation conditions as mentioned above, but with sound forcing

approximately with the deviations of the mean values of the various phases from the sinusoidal fit curve of Fig. 5c.

\subsection{Flame motion from phase-averaged $\mathrm{OH}$ and $\mathrm{CH}_{2} \mathrm{O}$ LIF measurements}

As the flames in gas turbine burners are rather spread out, various quantities can be defined to represent their position and motion. For the observation of the flame motion, the absolute value of the flame position is of minor importance; 
rather a relative value that includes an arbitrary offset is required. In a first definition, the flame position is identified with the phase-averaged center of the OH LIF intensity in flow direction, here called center of mass (CM). This quantity is averaged along the radial coordinate $\mathrm{y}$, i.e. along the light sheet propagation, for the $\mathrm{CZ}$, as well as for the $\mathrm{BZ}$ and $\mathrm{TZ}$ of the combustion chamber. For the experiments described in the last paragraph of the previous sub-section, Fig. 5b, d show the motion of $\mathrm{CM}$ in the $\mathrm{CZ}$ as a function of the oscillation phase, without and with sound forcing, respectively. A sine function can well be fitted to the phase-averaged data, spatially integrated for each of the zones $\mathrm{CZ}, \mathrm{BZ}$ and the TZ. The total variations of the flame position $(\mathrm{CM})$ are $\Delta z_{\mathrm{fl}}=3.0$ and $6.4 \mathrm{~mm}$, respectively.

For the (forced) experiment of Fig. 4a, results for the flame motion in the sub-zones of $\mathrm{CZ}$ are presented in Fig. 6. They show that the phase-averaged flame motion has the character of a piston motion. One recognizes from the figure that the angle $\vartheta$ between flame front and $x-y$ plane does not vary strongly with the acoustic oscillation.

A few repeated series of phase-averaged measurements under identical experimental conditions were performed. Deviations of not more than $15^{\circ}$ for the phase angles for minimum flame position and maximum OH LIF intensity were found, which gives an indication on the accuracy of the determination of phase angles.

The phase-relation between the variation of the OH LIF intensity and the flame motion was studied by variations of inlet temperature, inlet flow velocity, global fuel-air ratio and mode of fuel injection. A correlation, however weak, between the phase angles of the OH LIF intensity and of the flame motion was found. For 17 out of the 19 investigated cases the maximum OH LIF intensities in the $\mathrm{CZ}$ occurred at phase angles that were between $75^{\circ}$ and $132^{\circ}$ larger than the ones of the backward zero crossing of the flame motion.
Thus, they turned out to be at about the phases of minimum flame position. (The other results differed by $\pm 10^{\circ}$ more.) In order to check the relation between the phase angles of the variation of the OH LIF intensity and the flame motion, an additional (acoustically forced) experiment at a slightly different burner (cp. Sect. 2) was performed, in order to determine the distribution of $\mathrm{CH}_{2} \mathrm{O}$ by LIF. Figure 7a shows a selection of single pulse LIF images of $\mathrm{CH}_{2} \mathrm{O}$; an image of a $\mathrm{CH}_{2} \mathrm{O}$ measurement averaged at a given phase is shown in Fig. 7b. Figure $7 \mathrm{c}$ shows the variation of the $\mathrm{CH}_{2} \mathrm{O}$ intensity during the acoustic period in the zone noted in Fig. $7 \mathrm{~b}$ ("shear layer zone", SZ). From the experiment with $\mathrm{CH}_{2} \mathrm{O}$ LIF, we found, in the SZ, a shift of $70^{\circ}$ between the phase angle of backward zero crossing and the phase angle of the maximum of the $\mathrm{CH}_{2} \mathrm{O}$ LIF intensity (Fig. 7c).

The findings that the phase angles of maximum LIF intensity and minimum flame position correlate in a given flame zone, reflects the relation between heat release rate $\Delta \dot{Q}$, burning velocity $v_{\mathrm{b}}$, and fuel concentration $c_{\text {fuel }}$, see Eq. (2). In the data analysis performed here, LIF intensities are considered to provide an approximate measure for the heat release rate. Careful interpretation is needed specifically when considering LIF intensities of $\mathrm{OH}$ as a measure for the heat release rate. The example of calculations for atmospheric laminar premixed combustion show (Glassmann 1996) that the $\mathrm{OH}$ concentration rises approximately proportional to the temperature at the boundary between fresh and burnt gases, but decreases slowly towards equilibrium afterwards, whereas the temperature still increases slightly. The local heat release rate can therefore not be obtained from the local OH LIF intensity.

In lean hydrocarbon flames $\mathrm{OH}$ is produced during the combustion process. The $\mathrm{OH}$ concentration initially surmounts the thermal equilibrium concentration, which is, however, quickly reached after the flame front. To a first
Fig. 6 a Radial positions of the center of mass of the OH LIF intensity in the central zone versus the axial position for one period of the dominant acoustic oscillation. The curves for subsequent phases are plotted with an increasing horizontal offset with respect to the curve at the phase of $0^{\circ}$. b Total motion of the flame in the central zone given as the amplitude of the center of mass between minimum and maximum axial positions

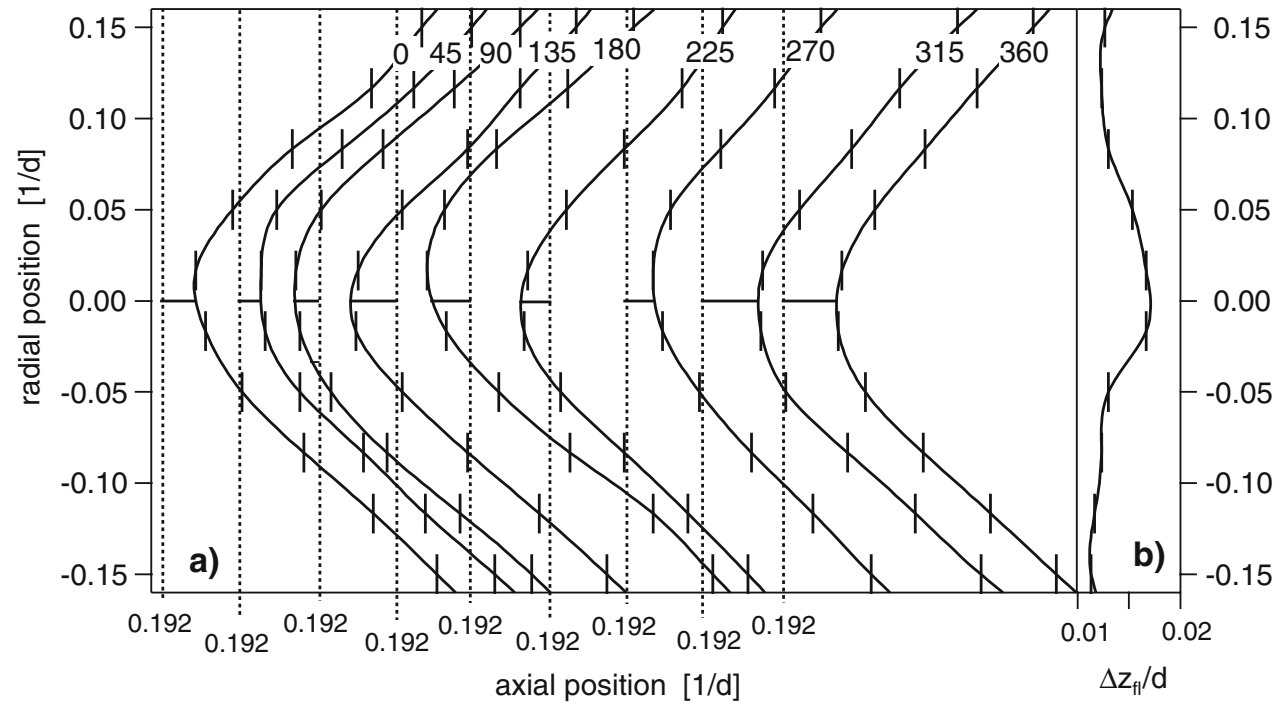


Fig. 7 a Selected single pulse $\mathrm{CH}_{2} \mathrm{O}$ LIF images at one phase angle (above, left). $\mathbf{b} \mathrm{CH}_{2} \mathrm{O} \mathrm{LIF}$ image averaged over all phases (above, right). c Variation of both the $\mathrm{CH}_{2} \mathrm{O}$ LIF intensity and center of mass and their corresponding sinusoidal fits (solid line) during one period of the dominant oscillation for the zone indicated with dashed lines in b (shear layer zone, SZ) (below). Acoustic forcing was applied in this experiment
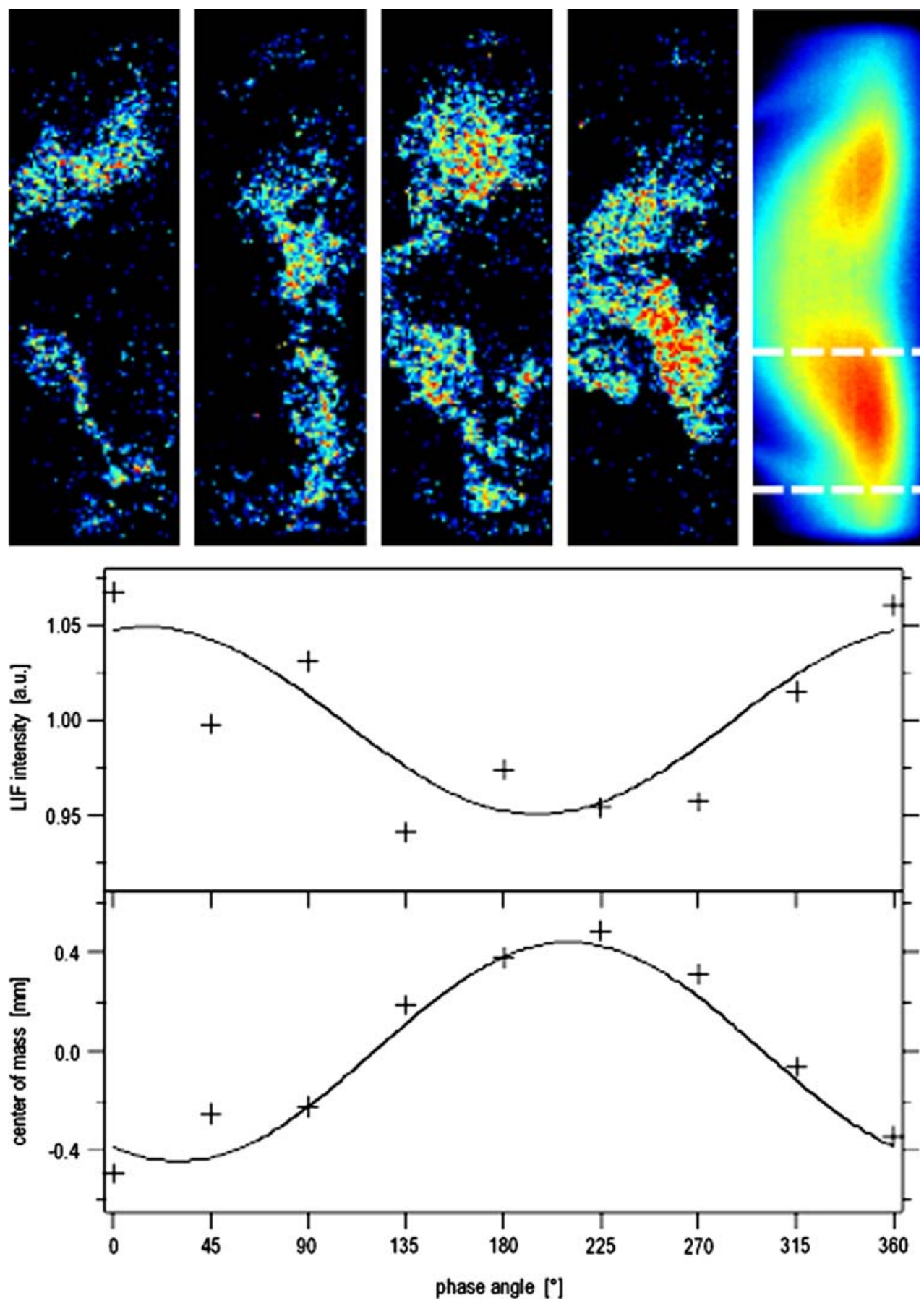

approximation the thermal equilibrium concentration of $\mathrm{OH}$ depends linearly on the concentration of $\mathrm{H}_{2} \mathrm{O}$ in the exhaust gas region, and exponentially on temperature. The concentration of $\mathrm{H}_{2} \mathrm{O}$ depends on its part linearly on fuelto-air ratio, whereas the temperature is a nonlinear function of $\phi$. Assuming complete combustion in lean flames, the heat release rate is directly related to the fuel-to-air ratio. The observed $\mathrm{OH}$ concentration is therefore related to the heat release, albeit in a complex form.
If one assumes in a model calculation that the $\mathrm{OH}$ concentration decays exponentially after its formation, a phase shift $\delta$ between the variation of the heat release and the $\mathrm{OH}$ concentration results. It lies between $0^{\circ}$ and $90^{\circ}$, depending on the ratio of the constant of decay to the angular sound frequency $\omega$. The phase shift $\delta$ is reduced if the $\mathrm{OH}$ is transported out of the observation volume, as it is the case for $\mathrm{OH}$ in the central zone. The phase shift was observed by Giezendanner et al. (2003) in a swirl- 
stabilized diffusion flame burner, comparing the phases of $\mathrm{OH}$ LIF measurements with those of $\mathrm{CH}_{2} \mathrm{O}$ LIF, CH LIF, or $\mathrm{OH}^{*} \mathrm{CL}$.

The main step in the analysis is to relate the flame motion in the inhomogeneous flow field, as observed in the laboratory, to the variation of the flame velocity relative to the gas flow. This is done in the "Appendix", using a number of assumptions and approximations, namely: neglect of phase-dependent gas flow velocity; homogeneity of the flow field in the combustor in the transverse axes (in $x-y$ plane); time-averaged flow direction parallel to $z$-axis; stationary external conditions; infinitely small thickness of the flame brush in propagation direction, and therefore equality between turbulent flame speed and burning velocity. The calculation shows that in the case of a spatially inhomogeneous flow with a large negative gradient of the mean flow velocity, the phase of the maximum flame velocity relative to the gas is at about the minimum flame position. On the other hand, in the case of a homogeneous flow field, the maximum flame velocity relative to the gas is at the backward zero crossing of the flame motion. The assumption that the gas flow velocity does not depend on the acoustic phase is an approximation. A phase-dependent modulation of the gas flow velocity is expected from the acoustic velocity. We refer here to Duan et al. (2005), who determined a periodic oscillation of the gas flow velocity in a gas turbine model combustor exhibiting thermoacoustic instability by means of phase-resolved laser Doppler anemometry.

Under the additional assumption that the phase difference between oscillations of $c_{\text {fuel }}$ and $v_{\mathrm{b}}$ is small, we conclude that the phase angle $\chi$ of maximum heat release rate has to be in the interval between backward zero crossing and minimum flame position. The assumption is justified if the main contribution to the variation of $v_{\mathrm{b}}$ is caused by variation of $c_{\text {fuel }}$. In the case of OH LIF the phase angle $\psi$ of the maximum LIF intensity is enlarged by the angle $\delta$, compared to $\chi$. Considering all the abovementioned effects, we find qualitative agreement between theoretical analysis and experimental data on the phase relation between the oscillations of the LIF intensity and of the flame motion. To get the order of magnitude for variations of the burning velocity, one may make the approximation of a homogeneous velocity field and neglect the phase-dependent gas flow velocity. For the flame motion of Fig. 5d, the calculation in the "Appendix" gives a variation of the flame velocity in axial direction $\delta \bar{v}_{r}=$ $0.06 u$ ( $u$ is the inlet gas flow velocity), if one inserts the total amplitude of the flame motion as obtained from the $\mathrm{CM}$ definition of flame position.

Instead of the center of mass, the rising slope of the $\mathrm{OH}$ LIF intensity profile could also be used as a measure for the flame position. Figure 8 shows the normalized profiles for

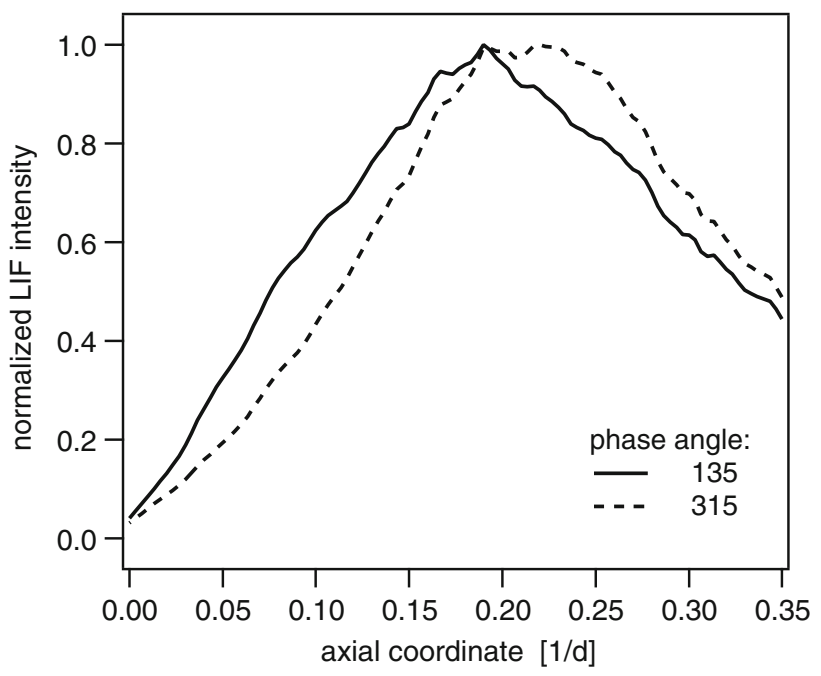

Fig. 8 Profiles of OH LIF intensity along the axial direction for the central zone at the phases $135^{\circ}$ and $315^{\circ}$ of the dominant acoustic oscillation

the central zone of the phase-averaged OH LIF intensity along the axial burner direction at the phase angles of $135^{\circ}$ and $315^{\circ}$ for the (acoustically forced) OH LIF series of Fig. 4a. The two phases represent about minimum and maximum positions of the flame. Plotting the axial positions of the rising edge versus the oscillation phase for the values $0.3-0.8$ (in intervals of 0.1 ) of the OH LIF intensities, normalized to their maximum, one finds $\Delta z_{\mathrm{fl}}=9 \mathrm{~mm}$ as a mean value, whereas the corresponding value for the motion of $\mathrm{CM}$ was $\Delta z_{\mathrm{fl}}=5 \mathrm{~mm}$. Figure 8 indicates that in the downstream part the difference in position of the $\mathrm{OH}$ regions diminishes for the different phase angles. Therefore, a difference in the values for $\Delta z_{\mathrm{fl}}$, using different definitions of the flame position, is expected. However, the phase of minimum flame position, i.e. the position closest to the burner edge, turned out to be unambiguous. Within the accuracy of the determination, the same values for both definitions of the flame position were obtained.

\subsection{Flame motion derived from single-pulse $\mathrm{OH}$ LIF images}

Instead of deriving the flame motion from phase-averaged measurements one may proceed by determining a flame front trace for each single-pulse image. This evaluation is based on the fact that the $\mathrm{OH}$ concentration rises steeply in the main heat release zone. In the present work, a median filter was applied iteratively to the raw images (of the experiment of Fig. 4a) in order to smooth out smaller holes. Each smoothed image was thereafter binarized with a threshold set at the level of $15 \%$ of the maximum image intensity value. The outline of the flame was obtained in 
the binarized image by applying a morphological operation, which returns 0 when all four connected pixels have the same value (either 0 or 1). Figure 9a shows a representative single-pulse OH LIF image; the diameter at the exit of the swirl burner is about $55 \%$ of the image height; Fig. $9 \mathrm{~b}$ shows the corresponding flame front trace, obtained by applying the binary image processing scheme.

Performing these operations for all 100 single-pulse images of a given phase of the dominant thermoacoustic oscillation, and adding the resulting flame fronts, an image of the distribution of the flame fronts is obtained. Figure 10a shows the images of the flame front distributions for a resolution of the phase angles of $45^{\circ}$. Average flame front motion can clearly be recognized. It should be noted that both the rise and drop in image intensity give a contribution to the flame front image. However, as these regions are typically well separated, this is not a serious limitation, and this analysis of the data is free from an artificial cutting off of lines. In order to determine quantitatively the motion of the flame, the central section of the image was subdivided into 10 pixel high horizontal slices. For each of these slices, the contributions of flame front traces in the vertical extension (i.e. over the 10 pixels) were added to give an intensity function along the image width. The first hill after the burner exit was subsequently fitted with a Gaussian, and for each slice the axial position corresponding to the maximum value of the Gaussian was chosen as the flame position. In order to reduce the noise, the flame front positions of four such slices were averaged. In this way the flame position in the central part of the flame was determined. Figure 10b shows the variation of the flame position over a period of the dominant thermoacoustic oscillation. The phase angle of the minimum flame position in the central part of the flame is very close to the one derived from the motion of the center of mass in CZ. The amplitude of the sinusoidal motion obtained is $\Delta z_{\mathrm{fl}}=13 \mathrm{~mm}$, and thus, larger than the value from the CM motion in $\mathrm{CZ}$ and also larger somewhat than the value obtained from the rising slope in the phase-averaged images in CZ (cp. Sect. 3.2, last paragraph).

\subsection{Global heat release variation from $\mathrm{OH}^{*} \mathrm{CL}$}

Integration of the phase-averaged 2-D OH* $\mathrm{CL}$ signals, see Fig. 4 b, c, over the whole flame yields a measure (see below) for the total heat release rate at a specific phase angle. Consistent with the LIF measurements, the total CL intensity also varies sinusoidally during the period of a
Fig. 9 a Representative single pulse OH LIF image (left). b Flame front trace resulting from a (right) )
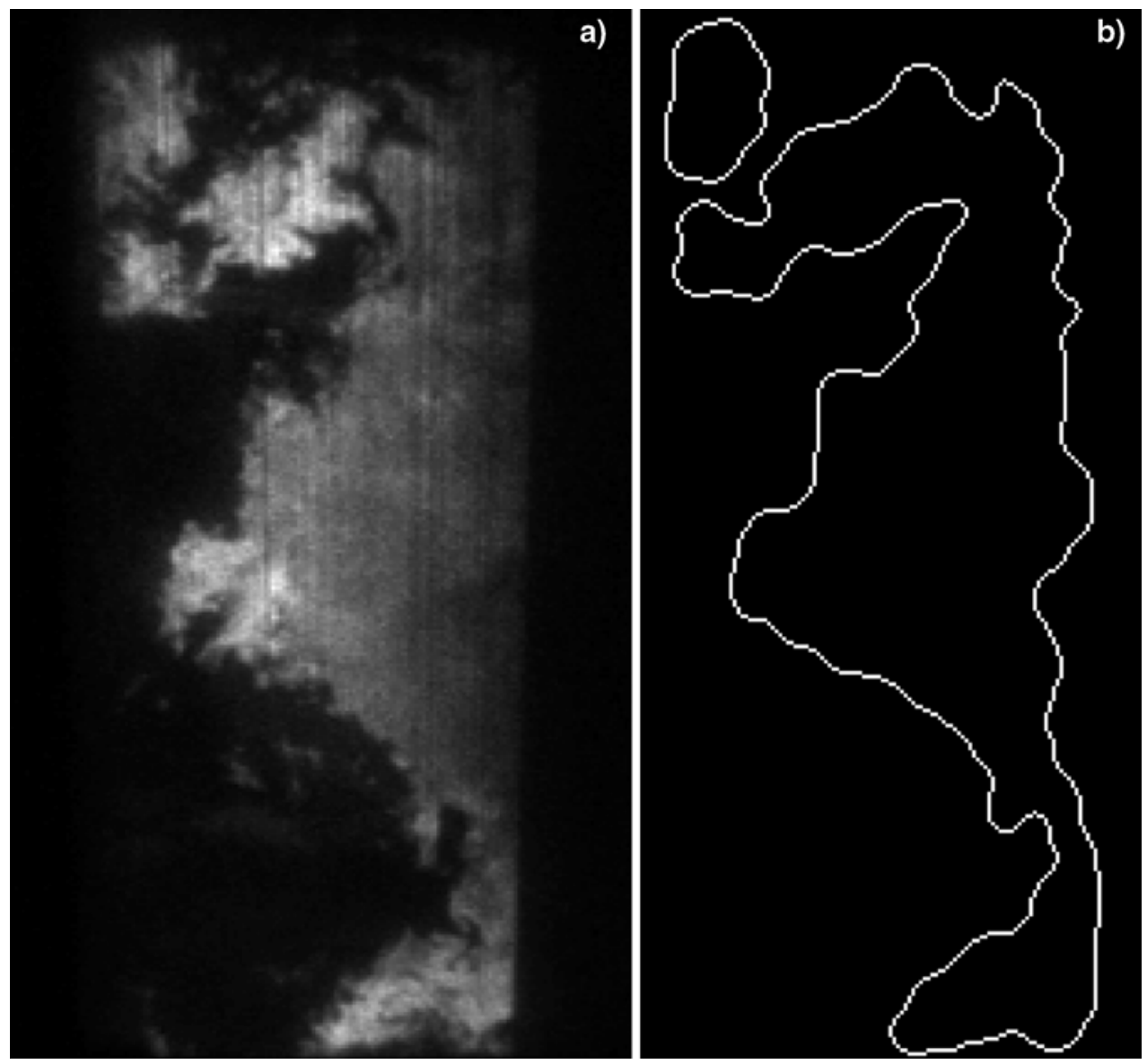
Fig. 10 a Superposition of phase-resolved flame front traces for phases of $0^{\circ}, 45^{\circ}, 90^{\circ}$, $135^{\circ}, 180^{\circ}, 225^{\circ}, 270^{\circ}$ and $315^{\circ}$. b Flame motion as function of phase angle obtained by technique of flame front tracing a)
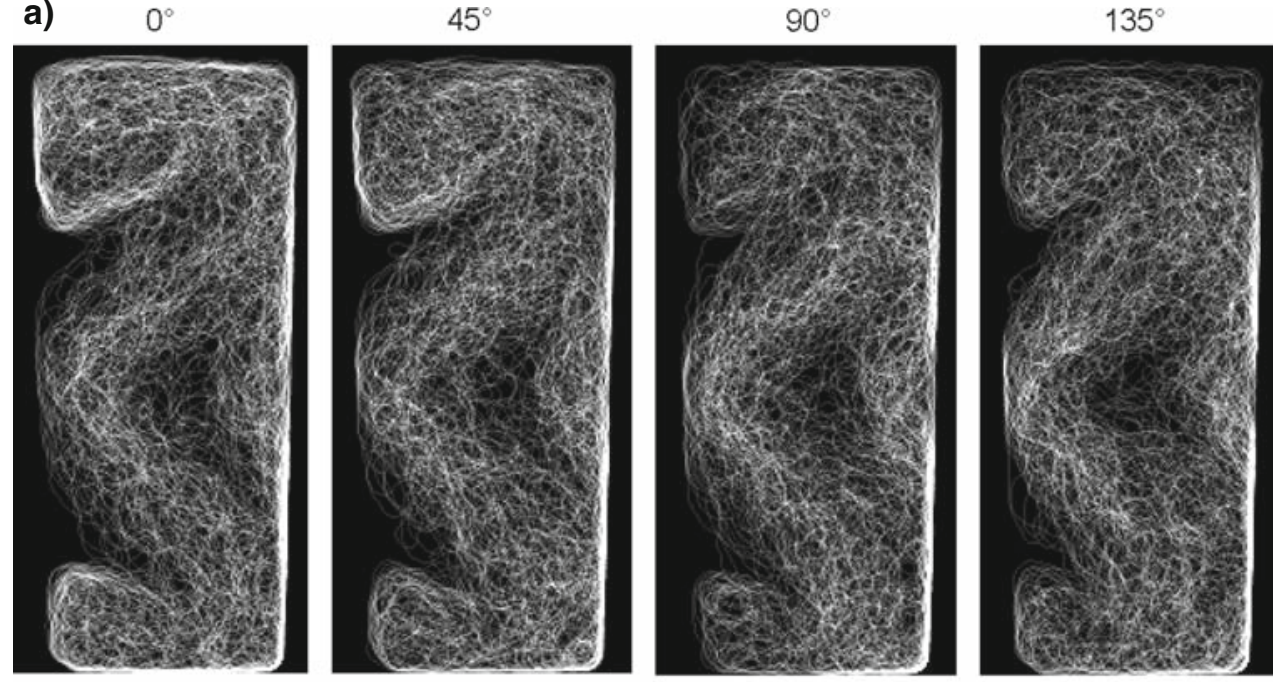

$180^{\circ}$

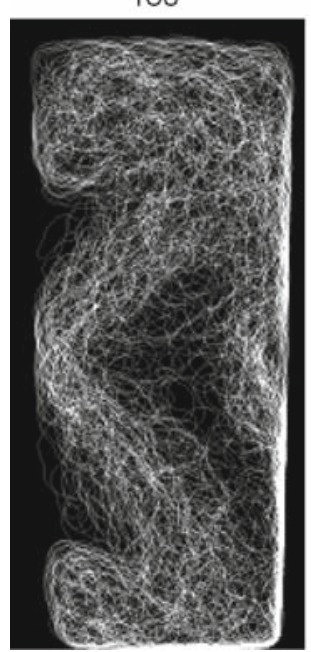

$225^{\circ}$

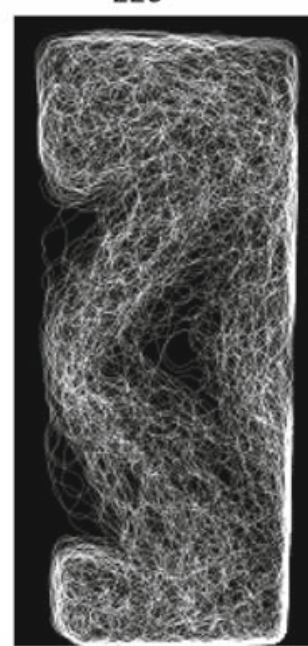

$270^{\circ}$
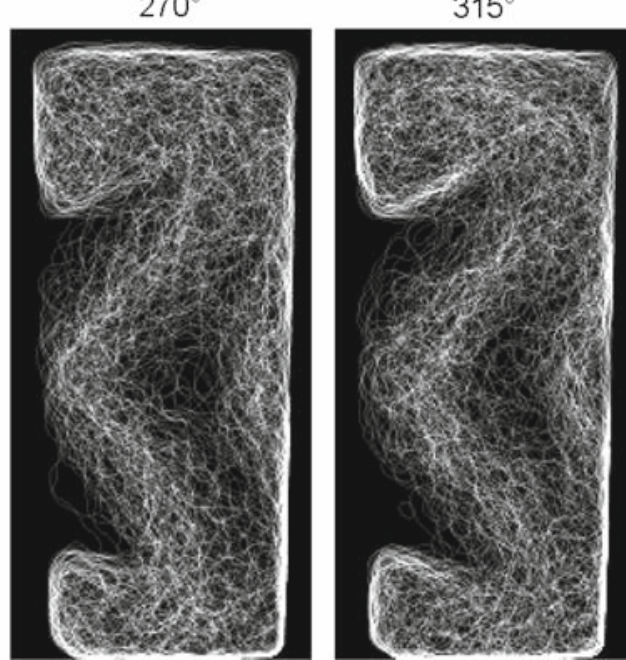

b)

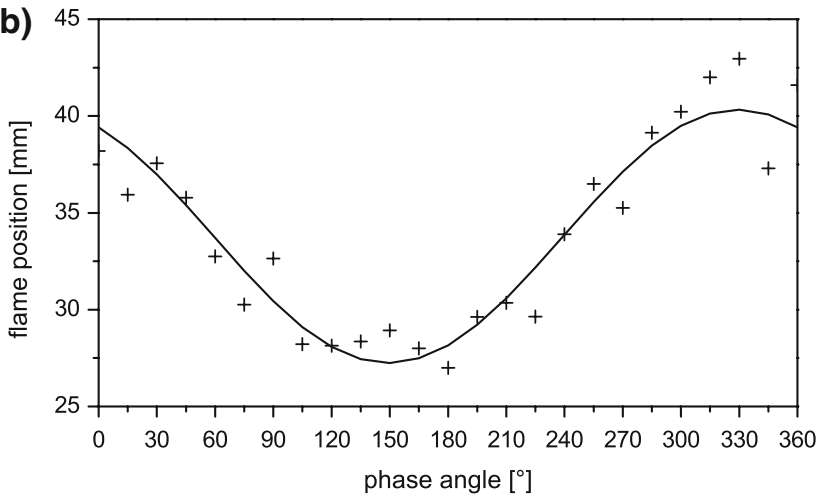

sound oscillation. The observed CL intensity variations over one oscillation period are \pm 14 and $\pm 13 \%$, respectively, for the two orientations of the burner, respectively, differing in azimuth angle by $90^{\circ}$. The phase angles of the maxima of the CL intensity differed by $21^{\circ}$. In fact, the measurements at the two burner orientations determine both the total CL intensity, i.e. the same quantity. The difference in the observed phase angles lies within the accuracy of determining phase angles (i.e. about $\pm 10^{\circ}$, cp. Sect. 3.2). The result of this measurement, as well as of 10 other measurements with $\mathrm{OH}^{*} \mathrm{CL}$ (for totally 6 different operation conditions), and of the measurement with $\mathrm{CH}_{2} \mathrm{O}$ LIF (cp. Sect. 3.2) give intensity maxima at phase angles between $5^{\circ}$ and $36^{\circ}$, with one exception only $\left(55^{\circ}\right)$. Thus, 
changing the mode of injection, or other operation conditions, moderately changes the phase relation to the acoustic oscillation. The phase relation indicates whether the heat release amplifies or weakens the acoustic oscillation (Rayleigh criterion).

We assume that a relevant if not overwhelming part of the heat release variations in thermoacoustic instabilities results from variations of the fuel-air equivalence ratio $\phi$ (cp. Sect. 3.5). In order to infer the heat release variation from the observed variations of the $\mathrm{OH}^{*} \mathrm{CL}$ intensities, we performed a series of $\mathrm{OH}^{*} \mathrm{CL}$ measurements with variation of the global $\phi$, and averaging over measurements at arbitrary acoustic phase angle. To cover the domain of interest for the thermoacoustic instabilities in the investigated burner, intensities $I_{\mathrm{CL}}(\phi)$ for the range of $\phi$ between 0.42 and 0.51 were determined, see Fig. 11. Approximately, a linear relationship between $\phi$ and $I_{\mathrm{CL}}(\phi)$ was observed. This domain of $\phi$ was not measured in the previous investigations of Higgins et al. (2001), Lee and Santavicca (2003), and Nori and Seitzman (2007).

The relation for the phase-resolved experiments between the variation of the normalized $\mathrm{OH}^{*} \mathrm{CL}$ intensity and the fuel-air equivalence ratio, and accordingly the variation of the heat release rate on the normalized $\mathrm{OH}^{*} \mathrm{CL}$ intensity, can now be determined approximately from the inverse derivative $\beta$ of the normalized function $I_{\mathrm{CL}}(\phi)$ at $\phi_{0}$, which is the average value of $\phi$ during the variation:

$\frac{\phi-\phi_{0}}{\phi_{0}}=\beta \frac{I_{\mathrm{CL}}(\phi)-I_{\mathrm{CL}}\left(\phi_{0}\right)}{I_{\mathrm{CL}}\left(\phi_{0}\right)}$.

$I_{\mathrm{CL}}\left(\phi_{0}\right)$ and $I_{\mathrm{CL}}(\phi)$ are the intensities of $\mathrm{OH}^{*} \mathrm{CL}$ for $\phi_{0}$ and for a value $\phi$ close to $\phi_{0}$, respectively. For the measurements given in Fig. 11, values for $\beta$ between 0.25 and 0.27 result, depending on $\phi_{0}$.

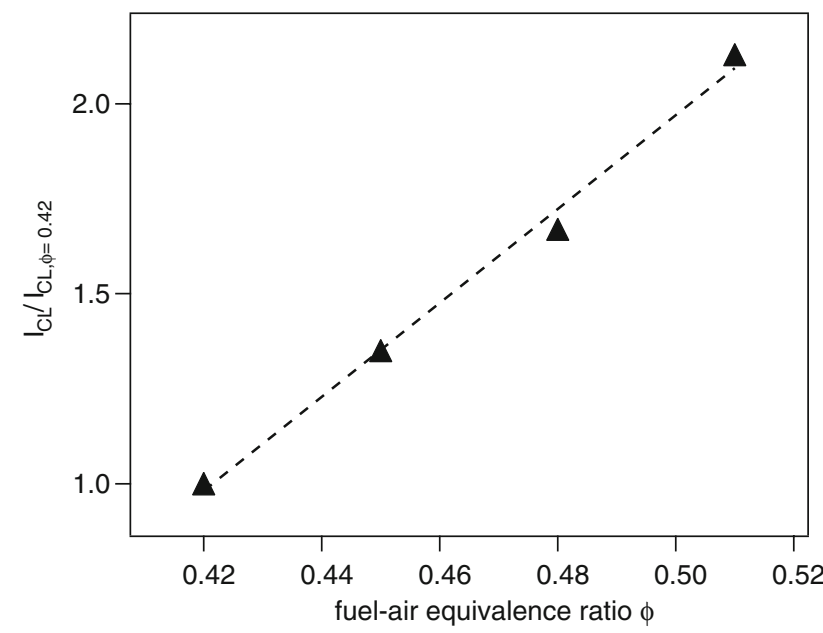

Fig. 11 Normalized $\mathrm{OH}^{*}$ chemiluminescence intensity $I_{\mathrm{CL}}$ experimentally determined as a function of the overall fuel-air equivalence ratio $\phi$
Taking into account these values of $\beta$, a variation of $\pm 13.5 \%$ in the $\mathrm{OH}^{*} \mathrm{CL}$ intensity corresponds to a variation of about $\pm 3.5 \%$ in the heat release rate during an oscillation period. For other operating conditions, variations of up to $\pm 35 \%$ of the $\mathrm{OH}^{*} \mathrm{CL}$ intensity were observed, that is, variations of heat release rate of up to about $\pm 9 \%$. According to the plane wave solution of Eq. (1), sound waves with peak pressure amplitudes of up to $2 \times 10^{2} \mathrm{~Pa}$ are generated in the flame zone by these variations of the heat release rate. These sound waves are superposed to the sound waves formed previously, and in a quasi-steady state they compensate for the dissipative losses of sound and for the radiation of sound out of the combustion chamber.

\subsection{Modulation of fuel concentration}

To check whether there is a feedback from the sound wave to the fuel injection, as assumed in the previous sub-sections, a (acoustically forced) tracer LIF experiment with acetone, added to the fuel, was performed. For this experiment a slightly modified burner configuration with optical access to the fuel/air mixing section was employed. Figure 12 shows the phase-averaged LIF intensity as a function of the phase angle. During one period of the sound oscillation the LIF intensity varies by about $\pm 6 \%$, which proves that the fuel injection is modulated by the sound wave for the given type of gas turbine burner. The observed temporal variation of $c_{\text {fuel }}$ in the mixing region propagates to the flame zone where it causes a periodic variation of the heat release rate. This coupling of the sound wave back to the flame is one of the important feedback mechanisms to build up thermoacoustic instability in the given burner type.

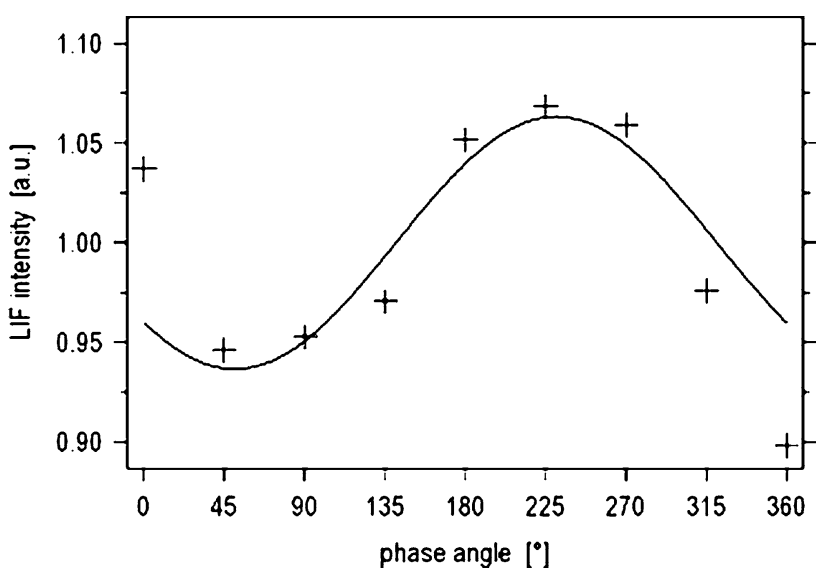

Fig. 12 Phase-averaged tracer LIF measurements of acetone-added to the fuel-in order to study the fuel modulation during an oscillation period and its sinusoidal fit (solid line) 


\section{Summary and conclusions}

We showed that phase-locked 2-D LIF and CL techniques are useful tools for the investigation of thermo-acoustic phenomena in commercial gas turbine burners, and thus for the further development of gas turbine burners. Main effects of acoustic instability studied in this paper are the phase-averaged flame motion and the phase-averaged variation of the heat release. Phase-locking was applied at the dominant frequency of acoustic oscillation. Phase-resolved data of the flame motion were obtained from phase-averaged images as also directly from single-pulse images. In order to distinguish the specific behavior of various zones of the flame, quantities were in part determined separately for the outer recirculation zones and the central flame zone. Flame motion, together with data on the time-dependent gas flow velocity, gives information on the variation of the burning velocity in unstable combustion.

We observed for a large number of operating conditions that the phase-averaged OH LIF intensity and the flame position of the various flame zones vary sinusoidally with the acoustic frequency. Oscillations are observed in the case of external sound forcing as well as without sound forcing. For identical conditions, phase angles of flame motion and $\mathrm{OH}$ LIF intensity yielded reproducible values within $\pm 10^{\circ}$. Measurements with phase-averaged $\mathrm{CH}_{2} \mathrm{O}$ LIF also showed a sinusoidal behavior of intensity variation and flame motion.

The amplitudes of flame motion in axial (i.e. the main flow) direction depend strongly on the definition of the flame position, i.e. center of mass versus rising slope in phase-averaged images, or flame front trace from singlepulse images. Phase angles of the flame motion, however, do not depend on the accuracy of measurement on the choice of definition. For the flame motion, interpreted as originating mainly from the variation of the burning velocity, we obtained qualitative agreement between experiment and theoretical analysis.

Phase-averaged $\mathrm{OH}^{*} \mathrm{CL}$ intensities integrated over the whole flame region vary sinusoidally by about \pm 13 to $\pm 35 \%$ around their mean values, depending on the specific operating conditions. By variations of the global fuel-air equivalence ratio $\phi$ we showed that there is an approximately linear dependence between variations of $\mathrm{OH}^{*} \mathrm{CL}$ intensities and variations of heat release in the relevant domain of very lean combustion with natural gas. From these calibration measurements it can be concluded that in the observed unstable combustion, phase-averaged heat release rates, spatially integrated, varied in the range of \pm 3.5 to $\pm 9 \%$.

One important feedback mechanism in the formation of the thermoacoustic instability in the given burner type is the modulation of the fuel concentration $c_{\text {fuel }}$ by the acoustic oscillation. This was shown by phase-locked LIF measurements of acetone in the mixing part of a slightly modified burner. The acetone had been added to the fuel as a tracer.

Acknowledgments Financial support by the Swiss Federal Office of Energy (BFE) and KTI (Kommission für Technologie und Innovation) is gratefully acknowledged. We thank O. Paschereit for planning and supervising the experiments, M. Zajadatz, R. Lachner, C. Motz, B. Paikert, T. Guntern for help during the experiments, especially for running the Alstom test rig, and P. Flohr, B. Schuermans, F. Biagioli, all of Alstom (Schweiz), V. Bellucci of PSI, and M. Füri of ETH Zürich for helpful discussions.

\section{Appendix: Quantitative approach to the phase- averaged flame motion in a simplified model}

We consider the heat release zone to be a volume characterized in transversal extent by the coordinates $x$ and $y$. In case of a piston-like motion of the flame, as we assume it, and which is suggested by experiment, the flame moves back and forth along the combustion chamber axis. To simplify the analysis, the (time-averaged) flow direction is supposed to be parallel to this axis. Actually, this is not the case for the flow field of the investigated burner, as there is non-negligible radial in-flow of reactants towards the center of the combustor, as was confirmed by LES calculations (Biagioli 2006). However, considering the whole $\mathrm{CZ}$, as it was defined above, we may assume that this inflow of reactants into $\mathrm{CZ}$ in transverse direction is small compared to the in-flow in axial direction.

The experimentally determined flame position of some section of the flame volume is defined as the average $z$-coordinate $z_{\mathrm{fl}}$ of the section considered, i.e. the $\mathrm{CZ}$ in our case. All time-dependent quantities are assumed to be phase-averaged with respect to the dominant acoustic oscillation with the angular frequency $\omega$. The laboratory flame propagation velocity $\dot{z}_{\mathrm{fl}}(t)$ is the difference between the gas flow velocity $v_{\text {gas }}^{\text {tot }}(t)$ at $z_{\mathrm{fl}}(t)$, and the propagation velocity $v_{r}(t)$, in opposite direction, of the flame relative to the gas flow:

$\dot{z}_{\mathrm{fl}}(t)=v_{\mathrm{gas}}^{\mathrm{tot}}\left(z_{\mathrm{fl}}, t\right)-v_{r}(t)$

We assume furthermore that $v_{r}(t)$ oscillates sinusoidally with the frequency $\omega$, the amplitude of the oscillation being $\delta \bar{v}_{r}$ :

$v_{r}(t)=\bar{v}_{r}[1+\delta \cos (\omega t-\alpha)]$.

For thick flames-as in our case- $-v_{r}(t)$ differs in general from the burning velocity $v_{\mathrm{b}}$, which is defined as volume of reactant gas burnt per unit of cross section and time unit. The temporal averages of $v_{r}(t)\left(\equiv \bar{v}_{r}\right)$ and $v_{\mathrm{b}}$, however, are equal. 
The gas flow velocity $v_{\text {gas }}^{\text {tot }}$ can be decomposed in a stationary part $v_{\text {gas, } 0}$, and the phase-dependent gas flow velocity $v_{\mathrm{var}}(t)$

$v_{\mathrm{gas}}^{\text {tot }}(t)=v_{\mathrm{gas}, 0}+v_{\mathrm{var}}(t)$.

The stationary gas flow velocity $v_{\text {gas }, 0}$ depends on the axial coordinate $z$. In our model case of a homogeneous flow field, parallel to the axis, the flame is situated close, in upstream direction, to the stagnation point of the gas flow. ${ }^{1}$ We approximate $v_{\text {gas }, 0}(z)$ linearly:

$$
\begin{aligned}
v_{\text {gas }, 0}(z) & =v_{\text {gas }, 0}\left(z_{0}\right)+\left(z-z_{0}\right) v_{\text {gas }, 0}^{\prime}\left(z_{0}\right) \\
& \equiv A_{0}-\left(z-z_{0}\right) A_{1} .
\end{aligned}
$$

The parameters $A_{0}$ and $A_{1}$ are positive and defined by the second equation above, and $z_{0}$ is chosen so that the relation $A_{0}=\bar{v}_{r}$ holds. From the equations above, one obtains the following equation:

$\dot{z}_{\mathrm{fl}}(t)+A_{1}\left\lfloor z_{\mathrm{fl}}(t)-z_{0}\right\rfloor=\bar{v}_{\mathrm{var}}(t)-\delta \bar{v}_{r} \cos (\omega t-\alpha)$.

Equation (A5) is a differential equation for $z_{\mathrm{fl}}$, if the parameters $\delta \bar{v}_{r}$ and $\alpha$ of the relative flame propagation velocity and $v_{\text {var }}(t)$ are known. On the other hand, if $z_{\mathrm{fl}}$ and $v_{\mathrm{var}}(t)$ are known experimentally, (A5) can be used to determine the parameters $\delta \bar{v}_{r}$ and $\alpha$.

The solution of Eq. (A5) with respect to $z_{\mathrm{fl}}$ is straightforward in the case that the phase-dependent gas flow velocity can be neglected. One obtains:

$z_{\mathrm{fl}}=\frac{\delta \bar{v}_{r}}{\omega\left(1+\zeta^{2}\right)^{1 / 2}} \sin (\omega t-\varphi)+z_{0}$,

with

$\zeta=\frac{A_{1}}{\omega}$

The angle $\varphi$ is determined by

$$
\begin{gathered}
\zeta \sin (\omega t-\varphi)+\cos (\omega t-\varphi) \\
\quad=-\left(1+\zeta^{2}\right)^{1 / 2} \cos (\omega t-\alpha) .
\end{gathered}
$$

Equation (A6) states that in an inhomogeneous flow field the amplitude of the flame motion is shrunk by the factor $\left(1+\zeta^{2}\right)^{1 / 2}$, compared to the case of homogeneous flow. We may distinguish two limiting cases:

1. $\zeta \ll 1$. We obtain $\alpha \approx \varphi+\pi$. This means that the maximum of the flame velocity relative to the gas is at the phase of the backward zero crossing of the flame.

2. $\zeta \gg 1$. We obtain $\alpha \approx \varphi+(3 \pi / 2)$. This means that the maximum of the flame velocity relative to the gas is at the phase of the minimum flame position.

\footnotetext{
1 This is not true in our real case of inhomogeneous flow field. Biagioli (2006) showed by numerical simulations that in the center of the combustion chamber the flame zone crosses the recirculation zone having negative axial flow velocity.
}

An approximation to Eq. (A6), valid for large $\zeta$, is obtained with the following simple argument: In general, at the turning points of the flame motion, $z_{\mathrm{fl}, \max }$ and $z_{\mathrm{fl}, \min }$, the flame propagation velocity relative to the gas is equal to the gas flow velocity. For large $\zeta$, i.e. for large $A_{1}$ compared to $\omega$, we may assume that approximately the following equation is true:

$\mathrm{v}_{\text {gas }, 0}\left(z_{\mathrm{fl}, \text { min }}\right)-\mathrm{v}_{\text {gas }, 0}\left(z_{\mathrm{fl} 1, \max }\right)=2 \delta \bar{v}_{r}$.

From the definition of the derivative $A_{1}$ in Eq. (A6) follows

$A_{1} \Delta z_{\mathrm{fl}}=2 \delta \bar{v}_{r}$

where by definition

$\Delta z_{\mathrm{fl}}=z_{\mathrm{fl}, \max }-z_{\mathrm{fl}, \min }$.

Thus, for $\zeta \gg 1$ results, in agreement with Eq. (A6)

$\Delta z_{\mathrm{fl}}=\frac{2 \delta \bar{v}_{r}}{\omega \zeta}$.

\section{References}

Bellows BD, Neumeier Y, Lieuwen T (2006) Forced response of a swirling, premixed flame to flow disturbance. J Prop Power 22:1075-1084

Bellows BD, Bobba MK, Forte A, Seitzman JM, Lieuwen T (2007) Flame transfer function saturation mechanisms in a swirlstabilized combustor. Proc Combust Inst 31:3181-3188

Biagioli F (2006) Stabilization mechanism of turbulent premixed flames in strongly swirled flows. Comb Theory Modell 10:389 412

Biagioli F, Güthe F, Schuermans B (2007) Combustion dynamics linked to flame behaviour in a partially premixed swirled industrial burner. In: Proceedings of seventh Mediterranean combustion symposium

Candel S (2002) Combustion dynamics and control: progress and challenge. Proc Combust Inst 29:1-28

Döbbeling K, Hellat J, Koch H (2005) 25 years of BBC/ABB/Alstom lean premix combustion technologies. In: Proceedings of ASME Turbo Expo (paper GT2005-68269)

Dowling AP, Stow SR (2005) Acoustic analysis of gas-turbine combustors. In: Lieuwen T, Yang V (eds) Combustion instabilities in gas turbine engines: operational experience, fundamental mechanisms, and modelling. Progress in astronautics and aeronautics, chap 13, vol 210. American Institute of Aeronautics and Astronautics

Duan XR, Meier W, Weigand P, Lehmann B (2005) Phase-resolved laser Raman scattering and laser Doppler velocimetry applied to periodic instabilities in a gas turbine model combustor. Appl Phys B80:389-396

Ducruix S, Schuller T, Durox D, Candel S (2005) Combustion instability mechanisms in premixed combustors. In: Lieuwen $\mathrm{T}$, Yang V (eds) Combustion instabilities in gas turbine engines: operational experience, fundamental mechanisms, and modelling. Progress in astronautics and aeronautics, chap 9, vol 210. American Institute of Aeronautics and Astronautics

Ferguson D, Richards GA, Woodruff SD, Bernal S, Gautam M (2001) Effect of surface area variation on heat release rates in premixed flames. Paper presented at 2 nd joint meeting of the U.S. Sections of the Combustion Institute, March 2001 
Filatyev SA, Driscoll JF, Carter CC, Donbar JM (2005) Measured properties of turbulent premixed flames for model assessment, including burning velocities, stretch rates, and surface densities. Combust Flame 141:1-21

Flohr P, Schmitt P, Paschereit CO (2002) Mixing field analysis of a gas turbine burner. In: Proceedings of IMECE'02 (Paper IMECE2002-34317)

Giezendanner R, Keck O, Weigand P, Meier W, Meier U, Stricker W, Aigner M (2003) Periodic combustion instabilities in a swirl burner studied by phase-locked planar laser-induced fluorescence. Combust Sci Technol 175:721-741

Glassmann I (1996) Combustion, chap 4, 3rd edn. Academic Press, San Diego

Güthe F, Schuermans B (2007) Phase-locking in post-processing for pulsating flames. Meas Sci Technol 18:3036-3042

Hassa C, Heinze J, Stursberg K (2002) Investigation of the response of an airblast atomizer combustion chamber configuration on forced modulation of air feed at realistic operating conditions. In: Proceedings of ASME Turbo Expo 2002, paper GT-200230059

Higgins B, McQuay MQ, Lacas F, Rolon JC, Darabiha N, Candel S (2001) Systematic measurements of $\mathrm{OH}$ chemiluminescence for fuel-lean, high-pressure, premixed, laminar flames. Fuel 80:6774

Huang Y, Wang S, Yang V (2005) Flow and flame dynamics of lean premixed swirl injectors. In: Lieuwen $\mathrm{T}$, Yang $\mathrm{V}$ (eds) Combustion instabilities in gas turbine engines: operational experience, fundamental mechanisms, and modelling. Progress in astronautics and aeronautics, chap 10, vol 210. American Institute of Aeronautics and Astronautics

Hubschmid W, Bombach R, Inauen I, Kreutner W, Schenker S, Zajadatz M, Motz C, Haffner K, Paschereit CO (2002) Sound generating flames of a gas turbine burner observed by laserinduced fluorescence. In: 30th International symposium on combustion in Sapporo. Abstracts of Work-in-progress posters, The Combustion Institute

Ingard U (1968) Acoustics. In: Condon EU, Odishaw H (eds) Handbook of physics, 2nd edn. McGraw-Hill, New York

Khanna VK, Vandsburger U, Saunders WR, Baumann WT (2002) Dynamic analysis of swirl stabilized turbulent gaseous flames. In: Proceedings of ASME Turbo Expo 2002, paper GT-200230061

Krebs W, Hoffmann S, Prade B, Lohrmann M, Büchner H (2002a) Thermoacoustic flame response of swirl flames. In: Proceedings of ASME Turbo Expo 2002, paper GT-2002-30065

Krebs W, Flohr P, Prade B, Hoffmann S (2002b) Thermoacoustic stability chart for high-intensity gas turbine combustion systems. Combust Sci Technol 174:99-128

Krüger U, Hüren J, Hoffmann S, Krebs W, Flohr P, Bohn D (2001) Prediction and measurement of thermoacoustic improvements in gas turbines with annular combustion system. J Eng Gas Turb Power 123:557

Lee JG, Santavicca DA (2003) Experimental diagnostics for the study of combustion instabilities in lean premixed combustors. J Prop Power 19:735-750

Lee JG, Santavicca DA (2005) Experimental diagnostics of combustion instabilities. In: Lieuwen $\mathrm{T}$, Yang $\mathrm{V}$ (eds) Combustion instabilities in gas turbine engines: operational experience, fundamental mechanisms, and modelling. Progress in astronautics and aeronautics, chap 16, vol 210. American Institute of Aeronautics and Astronautics

Lee SY, Seo S, Broda JC, Pal S, Santoro RJ (2000) An experimental estimation of mean reaction rate and flame structure during combustion instability in a lean premixed gas turbine combustor. Proc Combust Inst 28:775-782
Lieuwen T (2005) Physics of premixed combustion-acoustic wave interactions. In: Lieuwen T, Yang V (eds) Combustion instabilities in gas turbine engines: operational experience, fundamental mechanisms, and modelling. Progress in astronautics and aeronautics, chap 12, vol 210. American Institute of Aeronautics and Astronautics

Lieuwen T, Yang V (eds) (2005) Combustion instabilities in gas turbine engines: operational experience, fundamental mechanisms, and modelling. Progress in astronautics and aeronautics, vol 210. American Institute of Aeronautics and Astronautics

Menon S (2005 Acoustic-vortex-flame interactions in gas turbines. In: Lieuwen T, Yang V (eds) Combustion instabilities in gas turbine engines: operational experience, fundamental mechanisms, and modelling. Progress in astronautics and aeronautics, chap 11, vol 210. American Institute of Aeronautics and Astronautics

Nori VN, Seitzman JM (2007) Chemiluminescence measurements and modeling in syngas, methane and jet-A fueled combustors. Paper AIAA 2007-466, presented at the 45th AIAA Aerospace Sciences Meeting, Reno, Nevada

Paschereit CO, Gutmark E, Weisenstein W (1999) Coherent structures in swirling flows and their role in acoustic combustion control. Phys Fluids 11:2667-2678

Paschereit CO, Gutmark E, Weisenstein W (2000) Excitation of thermoacoustic instabilities by interaction of acoustics and unstable swirling flow. AIAA J 38:1025-1034

Paschereit CO, Flohr P, Schuermans B (2001) Prediction of combustion oscillations in gas turbine combustors. Paper AIAA 20010484, presented at the 39th AIAA Aerospace Sciences Meeting, Reno, Nevada

Paschereit CO, Schuermans B, Polifke W, Mattson O (2002) Measurements of transfer matrices and source terms of premixed flames. J Eng Gas Turb Power 124:239-247

Paul PH, Najm HN (1998) Planar laser-induced fluorescence imaging of flame heat release rate. Proc Combust Inst 27:43-50

Poinsot T, Veynante D (2001) Theoretical and numerical combustion. Edwards, Philadelphia

Poinsot TJ, Trouve AC, Veynante DP, Candel S, Esposito EJ (1987) Vortex driven acoustically coupled combustion instabilities. J Fluid Mech 177:265

Polifke W, Flohr P, Brandt M (2000) Modelling of inhomogenously premixed combustion with an extended TFC model. In: Proceedings of ASME Turbo Expo 2000, paper 2000-GT-0135

Schenker S, Bombach R, Inauen A, Kreutner W, Hubschmid W, Haffner K, Motz C, Schuermans B, Zajadatz M, Paschereit CO (2003) 2-D LIF measurements of thermo-acoustic phenomena in lean premixed flames of a gas turbine combustor. Inst Phys Conf Ser 177:215-220

Schneiders T, Hoeren A, Michalski B, Pfost H, Scherer V, Koestlin B (2001) Investigation of unsteady gas mixing processes in gas turbine burners applying a tracer LIF method. In: Proceedings of ASME Turbo Expo 2001, paper 2001-GT-0049

Schuermans B, Bellucci V, Güthe F, Meili F, Flohr P, Paschereit CO (2004) A detailed analysis of thermoacoustic interaction mechanisms in a turbulent premixed flame. In: Proceedings of ASME Turbo Expo 2004, paper GT2004-53831

Schuermans B, Güthe F, Scivos A, Voges M, Willert C (2006) Phaselocked PIV and $\mathrm{OH}$ chemiluminescence visualization on a swirl stabilized gas turbine burner. Paper presented at 12th international symposium on flow visualization

Venkataraman KK, Preston LH, Simons DW, Lee BJ, Santavicca DA (1999) Mechanism of combustion instability in a lean premixed dump combustor. J Prop Power 15:909

Zimont VL, Lipatnikov AN (1995) A model of premixed turbulent combustion and its validation. Chem Phys Rep 14:993-1025 